\title{
Ultrasonography: a method used for pregnancy imaging of the fire salamander (Salamandra salamandra)
}

\author{
A. Najbar' ${ }^{1}$ Z. Kiełbowicz², J. Szymczak², M. Ogielska1 \\ ${ }^{1}$ Department of Evolutionary Biology and Conservation of Vertebrates, \\ University of Wrocław, Sienkiewicza 21, 50-335 Wrocław, Poland \\ ${ }^{2}$ Department of Surgery, Faculty of Veterinary Medicine, \\ Wrocław University of Environmental and Life Sciences, \\ Pl. Grunwaldzki 51, 50-366 Wrocław, Poland
}

\begin{abstract}
Ultrasound imaging has more frequently been used in veterinary medicine of amphibians and reptiles. In this study, we have verified the usefulness of ultrasound imaging in pregnancy determination of the fire salamander Salamandra salamandra. We have also undertaken to estimate the number of larvae and their developmental stage directly in the oviducts. Three gravid females from Lower Silesia (southern Poland) were examined. Due to the small size of the scanned animals, and the particular arrangement of embryos in the oviducts and ultrasound beams dispersal, the method proved to be inaccurate. Therefore, the minimum number of well-visualized larvae was determined. The maximum number of larvae was established on the basis of the visible fragments of embryos. After birth, we found that the number of larvae born was included in the „min-max”range in only one case. In the remaining two salamanders the number of larvae was higher than estimated in 3 to 7 individuals. The results showed that ultrasound imaging allows the minimum number of larvae in salamander; oviducts to be specified. However, total length measurements were possible only for single and clearly visible embryos.
\end{abstract}

Key words: larval development, pregnancy imaging, Salamandra salamandra, ultrasonography

\section{Introduction}

Ultrasound imaging is an effective, safe and non-invasive method used in veterinary medicine in different groups of animals. It is common in mammals (Haibel 1990, Hildebrandt et al. 2000), and is increasingly used also in medicine and scientific research of wild animals such as lizards (Martinez-Torres et al.
2006, Gilman and Wolf 2007), snakes (Bonnet et al. 2008) and turtles (Valente et al. 2008). In amphibians, it has been used to visualize internal organs (Schildger and Triet 2001), to determine the sex of the Chinese giant salamander Andrias davidianus (Li et al. 2010) and to study the reproductive physiology of Bufo americanus (Johnson et al. 2002). In 2013, Krause et al. (2013) characterized ultrasound as an effective tool

Correspondence to: A. Najbar, e-mail: anna.najbar@uwr.edu.pl 


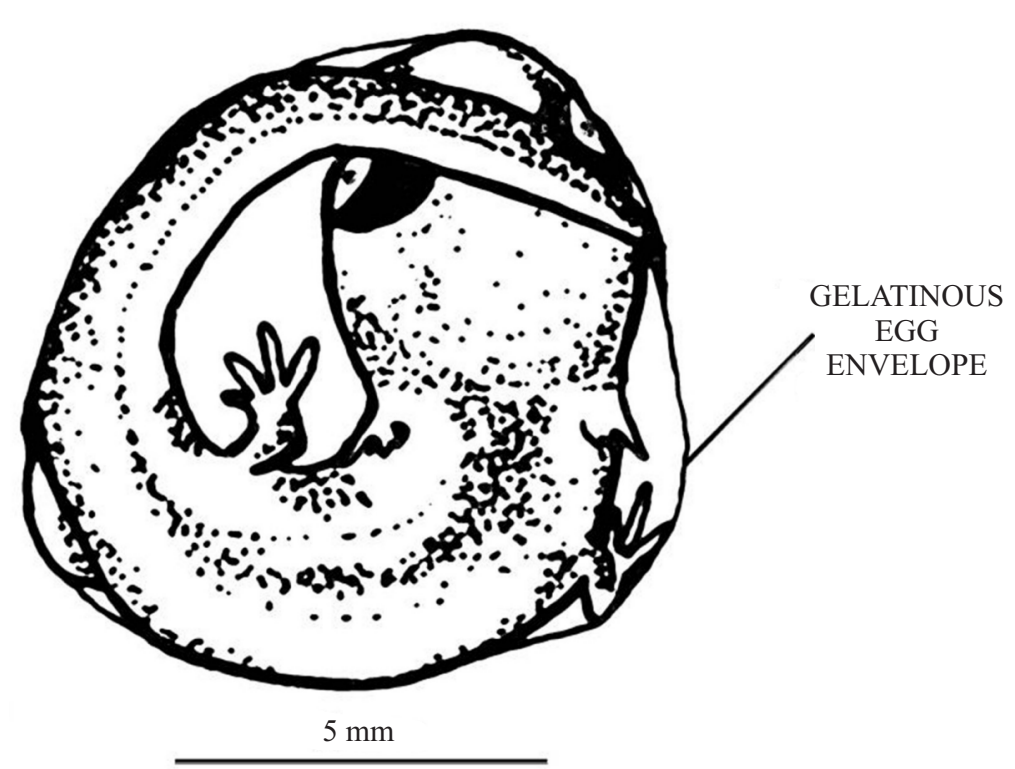

Fig. 1. Schematic drawing of Salamandra salamandra larva shortly after birth but before hatching from its gelatinous egg envelope.

in pregnancy verification of the fire salamander Salamandra salamandra (Linnaeus, 1758). In the future, the use of a portable ultrasound machine in ,in situ; research may increase the efficiency of field study, reducing animal stress by eliminating not useful individuals from transport to the laboratory.

Salamandra salamandra belongs to ovoviviparous (larviparity) and viviparous (fully metamorposed individuals are born) urodeles and is a model species widely used in developmental biology research (Greven 1998, Thiesmeier 2004, Buckley et al. 2007, Zakrzewski 2007). Development of embryos takes place in the oviducts and in their final, enlarged and well-vascularized part - the uterus (Francis 1934, Greven and Guex 1994, Zakrzewski 2007). The degree of oviduct filling depends on the number and size of embryos. According to Zakrzewski (2007), the number of larvae in a single oviduct ranged from 16 to 36 (in total: from 33 to 71 for 8 females).

In the spring, immediately after leaving their winter hideouts, females migrate to streams or small water basins to give birth to the larvae (Thiesmeier 2004, Zakrzewski 2007). Substantially fewer births, if any, are observed in autumn (Thiesmeier 2004). The number of larvae born ranges from several to several dozen (Juszczyk 1987), and according to Głowaciński and Zakrzewski (2003) ranges from 30 to 70 . Their total length typically ranges from 25.2 to $30.2 \mathrm{~mm}$. Besides fully developed larvae, females also excrete dead, undeveloped embryos and unfertilized eggs (Zakrzewski 2007). The number of embryos in the initial and final stages of pregnancy may vary due to resorption of dead embryos, oophagy (egg eating) or adelphophagy (cannibalism inside the oviduct) (e.g. Joly 1968, Buckley et al. 2007, Zakrzewski 2007). Before the birth, the larvae are arranged tightly in the oviducts and concentrate in the enlarged sections located behind the cloaca (Francis 1934). Their bodies are rolled, the curvature of the head to the body is approximately $90^{\circ}$ (see Fig. 1) and half the length of the tail overlaps the head (Szabó 1962). Occasionally just before the birth, larvae may break the gelatinous egg envelope; the female then delivers stretched larvae (Zakrzewski 2007).

Pregnancy of the fire salamander is usually determined by body weight, shape, size and width of the abdomen. However, due to the poorly marked sexual dimorphism, the pregnancy may not be easily recognized (Zakrzewski 2007, Najbar A. - personal observ.). The degree of filling of the gastrointestinal tract with food may also be misleading in the assessment, especially when females are captured in the early stages of pregnancy (Krause et al. 2013, Najbar A. - personal observ.).

The aims of this study were as follows: 1) determination of the usefulness and effectiveness of ultrasound imaging in pregnancy verification of fire salamanders (Salamandra s. salamandra), temporarily kept in captivity; 2) an accurate estimation of the number of larvae in each oviduct; and 3) based on the detection of skeletal elements of embryos (best seen in ultrasound imaging), to measure the total length of highly visible larvae. We hypothesized that such measurements will allow to follow the development of embryos before birth to be followed or pregnancy stage to be determined. Repeated use of ultrasonog- 
Table 1. Sampling sites and body sizes of the fire salamander Salamandra salamandra females used for ultrasound examination.

\begin{tabular}{|c|c|c|c|c|}
\hline $\begin{array}{l}\text { Female } \\
\text { number }\end{array}$ & Locality & $\begin{array}{c}\text { GPS } \\
\text { coordinates }\end{array}$ & $\begin{array}{l}\text { Total length } \\
{[\mathrm{cm}]}\end{array}$ & $\begin{array}{c}\text { Weight } \\
\text { [g] }\end{array}$ \\
\hline 1 & Ślęża Landscape Park & $\begin{array}{l}50^{\circ} 52^{\prime} 18.90^{\prime \prime} \mathrm{N}, \\
16^{\circ} 40^{\prime} 56.60^{\prime \prime} \mathrm{E}\end{array}$ & 16.7 & 33.3 \\
\hline 2 & Śnieżnik Landscape Park, Złoty Stok & $\begin{array}{l}50^{\circ} 26^{\prime} 11.57^{\prime \prime} \mathrm{N} \\
16^{\circ} 51^{\prime} 47.25^{\prime \prime} \mathrm{E}\end{array}$ & 14.1 & 26.5 \\
\hline 3 & Śnieżnik Landscape Park, Złoty Stok & $\begin{array}{l}50^{\circ} 26^{\prime} 11.57^{\prime \prime} \mathrm{N} \\
16^{\circ} 51^{\prime} 47.03^{\prime \prime} \mathrm{E}\end{array}$ & 15.3 & 26.0 \\
\hline
\end{tabular}

raphy in gravid females of the fire salamander allowed the suitability and accuracy of the method in pregnancy development of small urodeles to be assessed.

\section{Materials and Methods}

\section{Study sites and conditions of temporary rearing}

Three potentially gravid female salamanders: females 1, 2 and 3 (for details see Table 1) were caught from two populations located in Lower Silesia (Southern Poland) in 2014. Female 1 was captured in the Ślęża Massif (Ślęża Landscape Park), while females 2 and 3 were from Złoty Stok (Śnieżnik Landscape Park) (Table 1). The individuals were weighed and the total length of the body (STL) was measured (Table 1).

Until birth, the females were kept in glass terraria measuring 40x50x50 cm, filled with humid damp substrate, hiding places and a small water tank $(20 \times 20$ $\mathrm{cm}$ ). The temperature varied from 20 to $25^{\circ} \mathrm{C}$ and the humidity inside the terrariums was maintained at a minimum of $70 \%$. The salamanders were fed 2 times a week with earthworms, snails and crickets.

The salamanders were collected and the procedure was performed under permits from the Polish Ministry of the Environment (DOP-oz.6401. 02.24.2013.JRO), the Regional Director for Environmental Protection (WPN.6401.183.2013.MK.1) and the II Local Ethics Commission in Wrocław (113/2014). No animals were killed. After all the procedures, the females were kept in temporary captivity under very good care and released to their natural habitats.

\section{Ultrasound imaging procedure}

The ultrasound procedure was performed using a non-transferable Esaote MyLab Class C Vet machine (Esaote; Genova, Italy) with a linear probe frequency of $13 \mathrm{MHz}$. Coupling gel was applied on the scanned part of the animal's body, commonly used in veterinary medicine (Schildger and Triet 2001). Despite the fact that salamander skin is fragile and permeable to water and gases, no adverse reactions to the gel were noticed (Schildger and Triet 2001, Krause et al. 2013).

Initially, quick verification of pregnancy was performed only for female 1 . In this case, the salamander was gently immobilized by the hands of the person holding the animal. The ultrasound probe was applied to the bottom of the abdomen (near the cloaca) and the appearance of structural elements of larvae was observed on the screen. In addition, we scanned female 1 after delivery, in order to compare images of the body cavity. The second and detailed examination of all females was conducted under anesthesia.

To achieve accurate scans, we used short-term anesthesia by immersing the specimens in $0.5 \%$ buffered aqueous solution of tricaine methanesulfonate (MS-222, Sigma-Aldrich). The females were placed in a small container filled with MS-222 solution for approximately 6 to 8 minutes, until there was a lack of response to stimuli. The use of MS-222 has been verified as effective and safe for amphibians by Bentley and Heller (1965), Andreone et al. (1999), Crook and Whiteman (2006). The anesthetized salamander was put on a paper towel, with the ventral part upwards (in the ultrasound images the spine is placed on the reverse side). The deeper the tissues were penetrated by the ultrasound beam, the more accurate the images which were obtained. The left oviduct was scanned as the first, then the right. In both cases, scanning started from the cranial part of the body. The probe was moved from the top of the thorax through the lateral part, until loss of contact site between the probe and the body appeared as artifacts on the screen. The probe was also kept perpendicular to the scanned area to prevent overlapping images of two oviducts; it then was slowly moved on the salamander's body, as even a few millimeter movement of the probe completely changed the image seen. The procedure lasted about 15 minutes and the animals were immediately rinsed in fresh, cold water for approximately 30 minutes until total awakening. After all the procedures, the sala- 

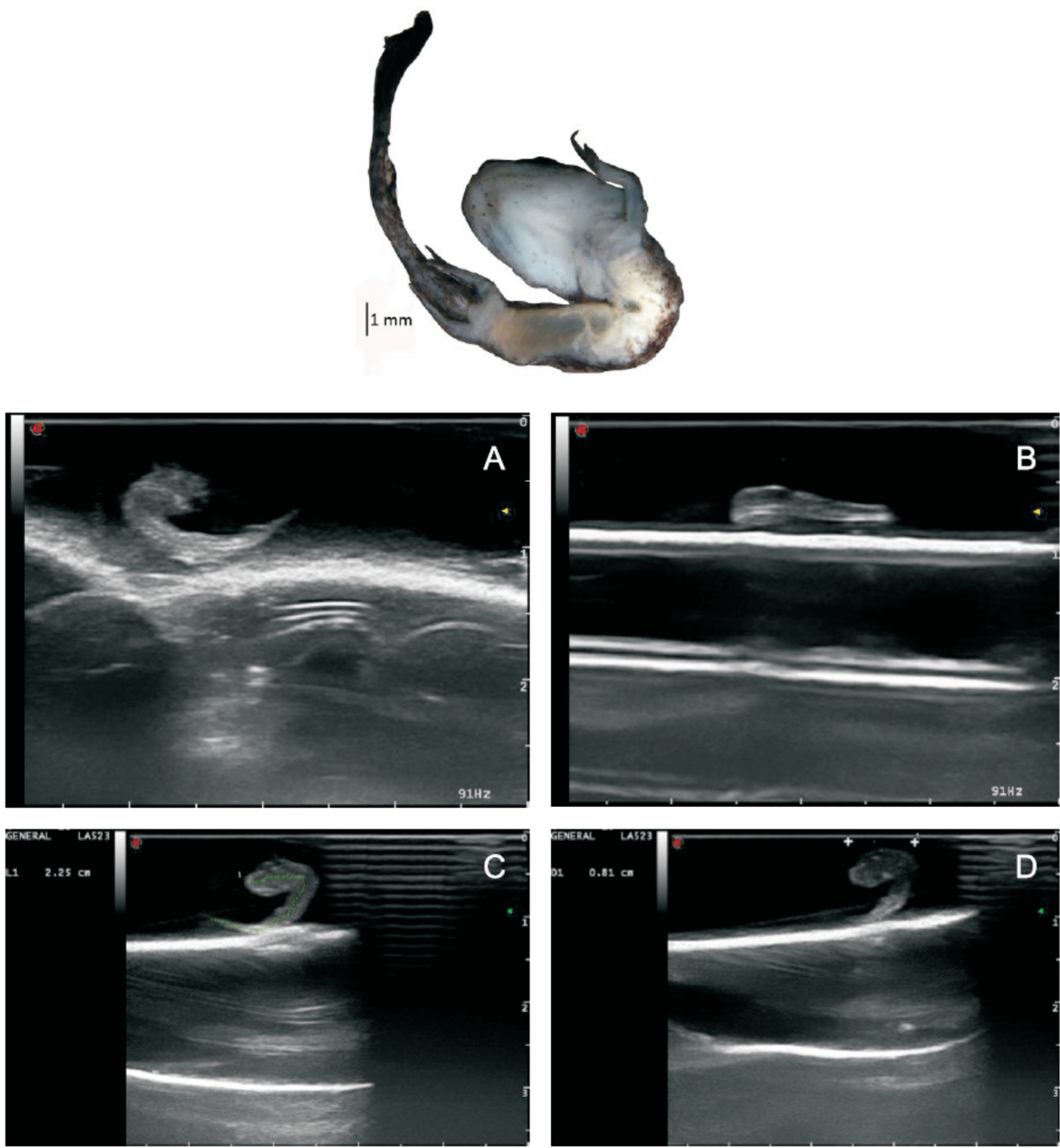

Fig. 2. Above: dead larva of the fire salamander (Salamandra salamandra) selected for ultrasound imaging. Below: obtained ultrasound pictures: A - head and thorax without visible end of tail, B - part of thorax and the entire tail, C - measurement of total length $(\mathrm{STL}=2.25 \mathrm{~cm}), \mathrm{D}-$ measurement of head length $(0.81 \mathrm{~cm})$.

manders were transferred to terrariums, where their behavior was regularly monitored.

The movement of the ultrasound probe on the fire salamander's body is highly significant. When the probe was hold in a longitudinal scan, the picture of the oviducts and larvae was not disturbed by other organs, because the wall of the oviduct remains in contact with the skin. While changing the angle of the probe to the scanning plane, other structures such as the heart, liver and ovaries filled with oocytes appeared.
Additionally, we performed ultrasound imaging of a single dead larva (born as a dead individual and preserved in $80 \%$ alcohol) (Fig. 2; picture taken under ZEISS Stemi SV 11 binocular). The larva had been placed in a latex glove filled with physiological saline, tied in order to avoid gas bubbles.

Material for further analysis has been saved as images (.bmp) and videos (.avi) showing the exact contents of each oviduct in different planes. Total body length measurements were also saved as images. The number of larvae in each oviduct was estimated using 

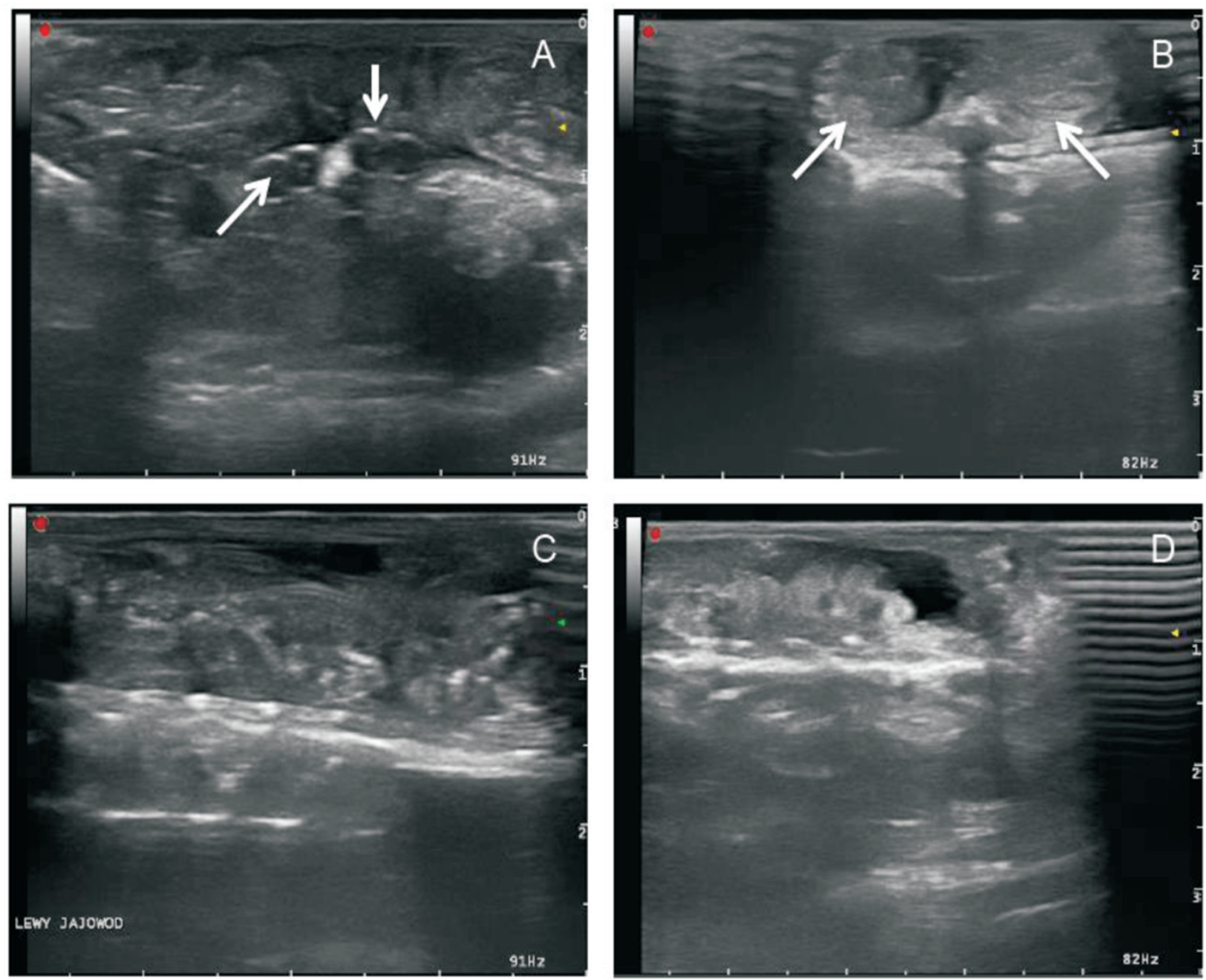

Fig. 3. Ultrasound pictures of internal organs of the fire salamander Salamandra salamandra females: A - oocytes, B - oviducts seen in cross-section, $\mathrm{C}$ - oviduct filled with larvae, D - abdominal cavity after birth.

only videos; larval skeletons or their fragments were precisely counted. The accuracy and usefulness of ultrasound imaging method was verified right after the births.

\section{Results}

Ultrasound imaging enabled the detection and diagnosis of the fire salamander's internal organs, as well as ovaries with maturing oocytes (Fig. 3A). The backbone with ribs was clearly visible in the ultrasound images. Transverse abdominal imaging revealed the oviducts filled with larvae (Fig. 3B). Larvae identification was based on the spine curves (Fig. 3C). In addition, we obtained the abdominal cavity image of female 1 after larvae birth (Fig. 3D).

The study enabled the confirmation of pregnancy in all scanned females. Verification of pregnancy was possible after a few seconds of probe application to the cloacal area. However, accurate illustration of oviducts required longer scanning time. In this case, the complete study of one female lasted from 10 to 16 minutes.

For both oviducts, the minimum number of larvae ranged from 13 (female 3 ) to 17 (female 2), and the maximum number of larvae ranged from 19 (female 3) to 29 (female 1). The actual number of larvae delivered differed significantly from the number estimated (Table 2). Only in the case of female 1, was the number of larvae born (22 individuals) included in the estimated range (18 to 29). For the other salamanders, the birth proved that the number of larvae was underestimated by between 3 to 7 larvae (see Table 2).

Measurement of total length of the larvae is presented in Fig. 4. Both head and tail were arranged perpendicular to the ultrasound beam, hence clear images were obtained. However, this is only one example of STL measurement. Other larvae were not fully visible and the pictures were incomplete. 
Table 2. Minimum (A) and maximum (B) number of larvae counted ,in utero"in the oviducts, the number of larvae delivered (C) and the differences between the number of estimated and delivered offspring (/C-A/, /C-B/, respectively)*.

\begin{tabular}{|c|c|c|c|c|c|}
\hline $\begin{array}{l}\text { Female } \\
\text { number }\end{array}$ & $\begin{array}{l}\text { Minimum number of } \\
\text { larvae in both oviducts } \\
\text { (A) }\end{array}$ & $\begin{array}{l}\text { Maximum number of } \\
\text { larvae in both oviducts } \\
\text { (B) }\end{array}$ & $\begin{array}{c}\text { Number of } \\
\text { larvae delivered } \\
\text { (C) }\end{array}$ & C-A* & C-B* \\
\hline 1 & 18 & 29 & 22 & 4 & 7 \\
\hline 2 & 17 & 25 & 32 & 15 & 7 \\
\hline 3 & 13 & 19 & 22 & 9 & 3 \\
\hline
\end{tabular}

* absolute value

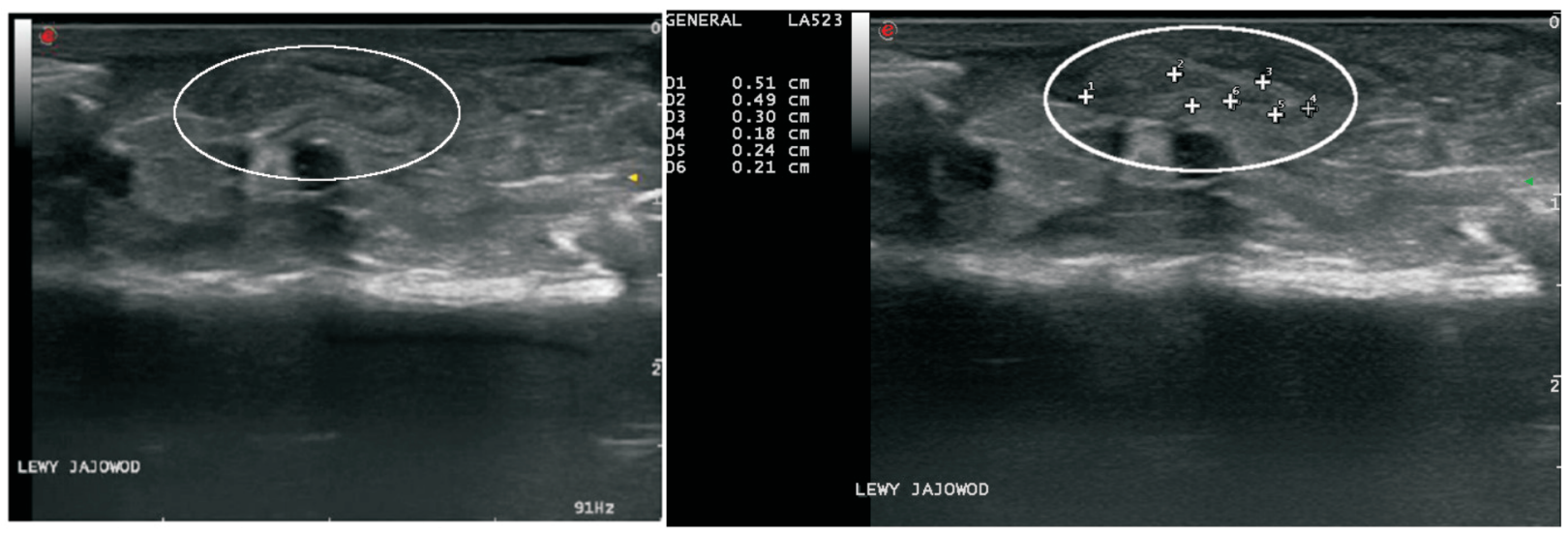

Fig. 4. Total length measurement $(\mathrm{STL}=1.93 \mathrm{~cm})$ of highly visible larva in the left oviduct of female 1. Left: left oviduct filled with larvae. Right: measurement points of clearly visible larva.

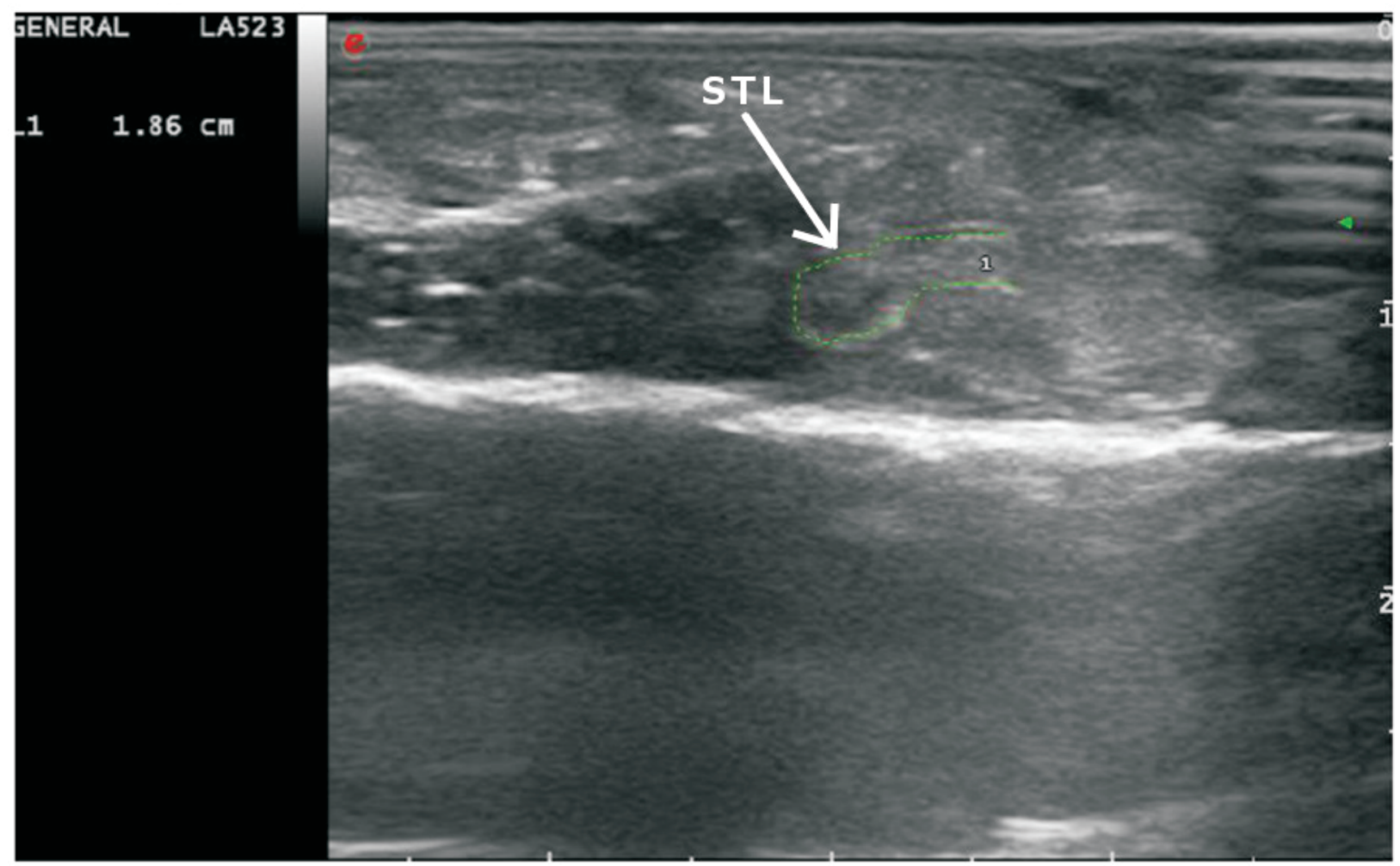

Fig. 5. Total length measurement $(\mathrm{STL}=1.86 \mathrm{~cm})$ of larva in the oviduct of female 2. 
Larva total length measurements (STL) were confirmed as inaccurate. One clearly visible larva of female 2 was selected for STL measurement; its total length was $18.6 \mathrm{~mm}$ (Fig. 5). Two days later, female 2 gave birth to 34 offspring with the length ranging from 24 to $29 \mathrm{~mm}$. The difference in STL between larva measured ,in utero" and the smallest larva born was $5.4 \mathrm{~mm}$. Therefore, no further measurements were carried out.

\section{Discussion}

In $2013-2014$, we caught 28 potentially pregnant females and transported them to the laboratory (unpublished). Only 8 females $(28.57 \%)$ gave birth to larvae in captivity. A similar problem was encountered by Krause et al. (2013), while in 2009-2012 the authors had captured 117 potentially pregnant females. However, only $33.33 \%$ of these delivered larvae. In both cases, pregnancy was determined on the basis of standard body shape observation.

The study confirmed that ultrasound imaging may quickly and effectively be used to determine pregnancy of $S$. salamandra. We used a non-portable ultrasound machine that requires transportation of animals. Use of mobile equipment (Krause et al. 2013) can save extra work and reduces additional stress during transport. In addition, control images (Fig. 2) revealed a sharp and undisturbed visualization of larva, necessary for further and correct ,in vivo" identification (Fig. 2A-B). The total length (STL) (Fig. 2C) and the length of the head (Fig. 2D) were measured.

Quick verification of pregnancy by ultrasound is safe and non-invasive, but can cause severe, short-term stress of the animal. No adverse effects were observed either during or after tests. However, the first salamander scanned (female 1) showed significant stress. The animal was hard to hold in a stable position and only blurred photographs were therefore achieved. Thus, further and more detailed scanning required anesthesia using MS-222. To avoid animal drowning during waking, it is recommended that its behavior should be carefully observed and the head should be supported with a piece of sponge or material to keep the nostrils above the water surface. The larvae had not been anesthetized as evidenced by their movements in the oviducts recorded as videos. In addition, immediately after the test, female 3 gave birth to an active larva.

Under anesthesia, both internal organs of females and skeletal fragments of larvae were clearly visible in the pictures. Gas bubbles in the body cavity are usually observed as hyperechogenic elements with comet tail artifacts (Fig. 3B, 3D) while fluids are hypoechogenic. However, it was impossible to determine the exact position of the embryos in the oviducts, and especially the number of embryos. Initially, we noticed that their spines visible in the images were stretched. This is the result of two-dimensional recording. Only fragments of larval bodies are visible and depend on the scanning plane of the salamander;s abdomen. Therefore, based only on the images, it was particularly difficult to determine the number of larvae in the oviducts. Due to their position inside envelopes, it is also difficult to correctly determine the head and tail of most visible larvae. Dissatisfaction with images obtained has forced us to rethink the techniques of consecutive scans. That is why we divided the oviducts into two sections and the scans were accurately recorded as videos. The probe was moved very slowly on both sides of the entire trunk. Scanning always started when the heart or the stomach wall were identified on the ultrasonography screen. This method enabled us to obtain three-dimensional, moving images of entire oviducts, which allowed more precise detection of individual larvae and their arrangement. Picture quality was the highest when scanning was performed on the ventral and lateral side because the oviduct is adjacent to the body integument mostly on the dorsal - lateral side.

In general, veterinarians do not undertake to determine the number of offspring of pregnant females in small animals such as cats and dogs, when more than three embryos are visible in the picture (Kealy and McAllister 2007). In a study of mice pregnancy development, Greco et al. (2013) noted that the total number of embryos is not visible during ultrasound imaging. In addition, our results generally revealed a lack of possibility to observe the entire larvae, due to the characteristic arrangement of embryos in the oviduct and their small size (Fig. 1). All the above-mentioned problems generate errors in the estimation of the actual number of larvae before birth. Estimation of the total number of larvae proved to be inaccurate. Therefore, due to the relatively unclear and fast-changing 3D images, we decided to determine the minimum and maximum number of embryos. However, only for female 1 was the number of larvae delivered included in the minimum-maximum range (Table 2).

In ultrasound imaging, the approximate total length (STL) can be determined based on the length of the larval spine, but only when it is suitably positioned and visible in the image. In this case, the method was generally ineffective. We found no possibility to measure the total length of most larvae due to the poor visibility of the whole body or the heads. Observation of complete larvae proves difficult, because the skull consists solely of cartilage (Zakrzewski 2007), and also due to the position of the embryos. The inaccuracy of this method was confirmed by measurements of STL of the larvae visible in the oviduct of female 2 (Fig. 5). Larvae born shortly after the test were at least $5.4 \mathrm{~mm}$ longer than the ultrasound measurements. 
In conclusion, understanding of prenatal mechanisms and phenomena occurring in S. salamandra oviducts can be used to determine the changes in the reproduction success of the species under the influence of various stressors, which may limit the ability to give birth to larvae, e.g. seasonal or temporary drying up of the streams. Due to the rapid global and local disappearance of amphibians (Blaustein et al. 1994, Collins and Storfer 2003), it is important to improve new methodology, which could be combined with methods of active protection. Although the ultrasound method proved to be inaccurate in conducting specific studies of the reproductive biology of $S$. salamandra, this study clarified the need for improvement, for example using more accurate equipment.

\section{Acknowledgements}

We thank two anonymous reviewers for useful comments on the manuscript. We also thank Bartłomiej Najbar and Piotr Kierzkowski for help during the research. The paper was financed by the Faculty of Veterinary Medicine at the University of Environmental and Life Sciences in Wrocław.

\section{References}

Andreone F, de Michelis S, Clima V (1999) A montane amphibian and its feeding habits: Salamandra lanzai (Caudata, Salamandridae) in the Alps of northwestern Italy. Ital J Zool 66: 45-49.

Bentley PJ, Heller H (1965) The water-retaining action of vasotocin on the fire salamander (Salamandra maculosa): the role of urinary bladder. J Physiol 181: 124-129.

Blaustein AR, Wake DB, Sousa WP (1994) Amphibian Declines: Judging Stability, Persistence, and Susceptibility of Populations to Local and Global Extinctions. Conserv Biol 8: 60-71.

Bonnet X, Akoka S, Shine R, Pourcelot L (2008) Disappearance of eggs during gestation in viviparous snake (Vipera aspis) detected using non-invasive techniques. Acta Herpetol 3: 129-137.

Buckley D, Alcobendas M, García-Parıs M, Wake MH (2007) Heterochrony, cannibalism, and the evolution of viviparity in Salamandra salamandra. Evol Dev 9: 105-115.

Collins JP, Storfer A (2003) Global amphibian decline: sorting the hypotheses. Divers Distrib 9: 89-98.

Crook AC, Whiteman HH (2006) An Evaluation of MS-222 and Benzocaine as Anesthetics for Metamorphic and Paedomorphic Tiger Salamanders (Ambystoma tigrinum nebulosum). Am Midl Natur J 155: 417-421.

Francis ETB (1934) The anatomy of the salamander. Clarendon Press, Oxford.

Gilman CA, Wolf BO (2007) Use of portable ultrasonography as a nondestructive method for estimating reproductive effort in lizards. J Exp Biol 210: 1859-1867.
Głowaciński Z, Zakrzewski M (2003) Salamandra plamista Salamandra salamandra (Linnaeus, 1758). In: Głowaciński Z, Rafiński J (eds) Atlas płazów i gadów Polski. Status - Rozmieszczenie - Ochrona. Biblioteka Monitoringu Środowiska, Warszawa - Kraków, pp 27-29.

Greco A, Ragucci M, Coda AR, Rosa A, Gargiulo S, Liuzzi R, Gramanzini M, Albanese S, Pappata S, Mancini M, Brunetti A, Salvatore M (2013) High Frequency Ultrasound for In Vivo Pregnancy Diagnosis and Staging of Placental and Fetal Development in Mice. PLoS One 8: e77205.

Greven H (1998) Survey of the Oviduct of Salamandrids With Special Reference to the Viviparous Species. J Exp Zool 282: 507-525.

Greven H, Guex GD (1994) Structural and Physiological Aspects of Viviparity in Salamandra salamandra. Mertensiella 4: 139-160.

Haibel GK (1990) Use of ultrasonography in reproductive management of sheep and goat herds. Vet Clin North Am Food Anim Pract 6: 597-613.

Hildebrandt TB, Hermes R, Jewgenow K, Göritz F (2000) Ultrasonography as an important tool for the development and application of reproductive technologies in non-domestic species. Theriogenology 53: 73-84.

Johnson CJ, Vance CK, Roth TL, Kouba AJ (2002) Oviposition and ultrasound monitoring of American toads (Bufo americanus) treated with exogenous hormones. Proceedings of American Association of Zoo Veterinarians, pp 299-301.

Joly P (1968) Données Ecologiques sur Salamandra tachetée Salamandra salamandra L. Annal Sc Natur Zool 10: 301-366.

Juszczyk W (1987) Płazy i gady krajowe. Płazy. PWN, Warszawa.

Kealy JK, McAllister H (2007) Diagnostic radiology and ultrasonography of the dog and cat. 1st Polish ed., Koper S (ed) Elsevier Urban \& Partner, Wrocław.

Krause ET, von Engelhardt N, Steinfartz S, Trosien R, Caspers BA (2013) Ultrasonography as a minimally invasive method to assess pregnancy in the fire salamander (Salamandra salamandra). Salamandra 49: 211-214.

Li PQ, Zhu BC, Wang YF, Xiang XJ (2010) Sex identification of Chinese giant salamander (Andrias davidianus) by Doppler B-ultrasound method. J Biol 27: 94-96.

Martinez-Torres M, Guzman-Rodriguez R, Cardenas-Leon M, Brunner-Reynaldo N (2006) Follicular development and ovulation determined by ultrasound imaging in the viviparous lizard Barisia imbricata (Reptilia: Anguidae). Southwest Nat 51: 401-406.

Schildger B, Triet H (2001) Ultrasonography in Amphibians. J Exot Pet Med 10: 169-173.

Szabó I (1962) Nahrungawhl und Nahrung des Gefflecken Feuersalamanders (Salamandra salamandra L.). Acta Zool Acad Sci Hung 8: 456-477.

Thiesmeier B (2004) Der Feuersalamander. Laurenti - Verlag, Bielefeld.

Valente AL, Parga ML, Espada Y, Lavin S, Alegre F, Marco I, Cuenca R (2008) Evaluation of Doppler ultrasonography for the measurement of blood flow in young loggerhead sea turtles (Caretta caretta). Vet J 176: 385-392.

Zakrzewski M (2007) Salamandra plamista. Rozmieszczenie, biologia i zagrożenia. Wydawnictwo Naukowe AP, Kraków. 